Federal Reserve Bank of Minneapolis

Research Department

\title{
Equilibrium and Government Commitment
}

\author{
Marco Bassetto* \\ Working Paper 624
}

September 2002

\begin{abstract}
How should a government use the power to commit to ensure a desirable equilibrium outcome? In this paper, I show a misleading aspect of what has become a standard approach to this question, and I propose an alternative. I show that the complete description of an optimal (indeed, of any) policy scheme requires outlining the consequences of paths that are often neglected. The specification of policy along those paths is crucial in determining which schemes implement a unique equilibrium and which ones leave room for multiple equilibria that depend on the expectations of the private sector.
\end{abstract}

\footnotetext{
*Bassetto, University of Minnesota and Federal Reserve Bank of Minneapolis. I am indebted to Florin Bidian, V. V. Chari, Harold Cole, Russell Cooper, Jeffrey Ely, Larry Jones, Christopher Phelan, and especially Narayana Kocherlakota for useful conversations and advice. I also benefited from comments received at various seminars and conference presentations. Financial support from the National Science Foundation (Grant \# 0095766) is gratefully acknowledged. The views expressed herein are those of the author and not necessarily those of the Federal Reserve Bank of Minneapolis or the Federal Reserve System.
} 


\title{
Equilibrium and Government Commitment*
}

\author{
Marco Bassetto ${ }^{\dagger}$
}

September 30, 2002

\begin{abstract}
How should a government use the power to commit to ensure a desirable equilibrium outcome? In this paper, I show a misleading aspect of what has become a standard approach to this question, and I propose an alternative. I show that the complete description of an optimal (indeed, of any) policy scheme requires outlining the consequences of paths that are often neglected. The specification of policy along those paths is crucial in determining which schemes implement a unique equilibrium and which ones leave room for multiple equilibria that depend on the expectations of the private sector.
\end{abstract}

\section{Introduction}

How should a government use its limited set of policy instruments to achieve desirable equilibrium outcomes?

\footnotetext{
*keywords: Government strategy, commitment, implementation, competitive equilibrium

${ }^{\dagger}$ Department of Economics, University of Minnesota, 271 19th Ave. S., Minneapolis, MN 55455, and Federal Reserve Bank of Minneapolis. I am indebted to Florin Bidian, V.V. Chari, Harold Cole, Russell Cooper, Jeffrey Ely, Larry Jones, Christopher Phelan and especially Narayana Kocherlakota for useful conversations and advice. I also benefited from comments received at various seminars and conference presentations. Financial support from the National Science Foundation (Grant \# 0095766) is gratefully acknowledged. The views expressed herein are those of the author and not necessarily those of the Federal Reserve Bank of Minneapolis, the Federal Reserve System or the NSF.
} 
While there is a vast literature that studies the features of optimal macroeconomic policy and the characteristics of the equilibria that it can attain, ${ }^{1}$ considerably less attention has been devoted to their implementation. Can the government adopt strategies that ensure that its preferred outcome will be the unique equilibrium? Is it instead possible that all the strategies that support a good outcome imply multiple equilibria, any of which may be triggered by the whims of private expectations? ${ }^{2}$

In the analysis of optimal policy, the standard framework follows from the pioneering work of Ramsey [19]. The Ramsey problem focuses only on the actual policy the government undertakes within an equilibrium and does not contain a full description of a government strategy. This is justified by the fact that most macroeconomic models assume a large number of agents, whose individual deviations are undetectable: as a consequence, within an equilibrium, each household takes government policy as given and independent of its own actions, and does not need to know the full strategy of the government. The Ramsey outcome is commonly viewed as the benchmark that the government could attain if it were able to commit, and is then compared to the equilibrium outcomes that prevail when commitment is impossible.

The simple examples of $\S 2$ show instead that knowledge of the full strategy is essential to establish uniqueness of the equilibrium the government is trying to achieve, even if it can commit in advance. In this paper I describe an alternative setup, where the question of uniqueness of the equilibrium can be addressed appropriately. Rather than being the choice of an unconditional action, commitment is the choice of the strategy that the government will unconditionally follow for the remainder of its interaction with the private sector. The essential difference between the Ramsey timing and what I will call the "Schelling timing" is captured by the following passage from Schelling [22]:

\footnotetext{
${ }^{1}$ For a recent survey, see Chari and Kehoe [6].

${ }^{2}$ The problem of equilibrium indeterminacy and its implications for implementation has received some attention in reference to monetary economics. Some of the early contributions in this area belong to Sargent and Wallace [21] and to Matsuyama [16, 17]. Clarida, Galí and Gertler [8] provide a survey of the recent literature on interest-rate rules and their determinacy properties. I will discuss in $\S 4.2$ the relationship between this literature and the formal treatment of implementation presented here.
} 
The threat differs from the ordinary commitment, however, in that it makes one's course of action conditional on what the other player does. While the commitment fixes one's course of action, the threat fixes a course of reaction, of response to the other player. The commitment is a means of gaining first move in a game in which first move carries an advantage; the threat is a commitment to a strategy for second move. $^{3}$

In macroeconomic games, the government faces a continuum of players rather than a single opponent. In such an environment, strategies that implement desirable outcomes do not usually take the nature of direct "threats", but achieve their aim in a more indirect way. For this reason, I will refer to them as "binding promises" instead.

Compared to the standard Ramsey problem, the analysis of binding promises attributes a much more prominent role to the constraints the government is forced to respect away from an equilibrium. These constraints limit the strategies the government can adopt, even when full commitment is assumed.

Studying the implementation problem has important policy implications. The appropriate policy advice differs radically depending on whether a strategy for implementing a desirable equilibrium exists. If it does, the appropriate advice calls for ensuring that the government adopts one such strategy: this typically calls for constraining policy, e.g. through the design of institutions such as independent central banks, so that the government is able to overcome any time-consistency temptation that may arise. If no such strategy exists, policy advice should instead explore new instruments that could be used to ensure the favorable outcome: this calls for giving the government more options than the ones it currently has.

In section 2, I introduce my remarks through two simple examples. Section 3 contains the general framework. The notion of a Ramsey outcome is introduced, and the implications of government commitment to actions vs. strategies are explored in detail. Section 4 discusses some applications in which the general framework can be fruitfully adopted, and section 5 concludes.

\footnotetext{
${ }^{3}$ Page 124 . Italics are from the original.
} 


\section{Two Simple Examples}

\subsection{Optimal Taxation}

This example is adapted from Fischer [12] and Chari and Kehoe [5] (CK from now on).

The economy has two periods, 1 and $2{ }^{4}$ In the first period, a continuum of households is endowed with $\omega$ units of a good that can be either consumed or invested. Each unit invested delivers $R>1$ units in period 2. Household preferences are $U\left(c_{1}, c_{2}, G\right)$, where $c_{1} \geq 0$ is consumption in period $1, c_{2} \geq 0$ is consumption in period 2 and $G$ is a public good that is provided by the government in the second period. I assume that $U$ is strictly concave in private consumption. Fischer [12] and CK assume that the government must finance an exogenously given level of spending $G^{*}$ in per capita terms, in which case the way $U$ depends on $G$ becomes redundant. To raise resources, the government uses a proportional tax on capital income $(\tau)$. The budget constraints for an individual household are thus:

$$
\begin{aligned}
& c_{1} \leq \omega-k \\
& c_{2} \leq R k(1-\tau)
\end{aligned}
$$

A competitive equilibrium for this economy is a vector $\left(\hat{c}_{1}, \hat{c}_{2}, \hat{k}, \hat{\tau}, \hat{G}\right)$ such that:

(i) given $\hat{\tau}$ and $\hat{G},\left(\hat{c}_{1}, \hat{c}_{2}, \hat{k}\right)$ solves the household maximization problem;

(ii) the government budget constraint holds:

$$
\hat{\tau} R \hat{k} \geq \hat{G}
$$

It is assumed that $G^{*}>0$ but that it is not too large, so that there exist competitive equilibria that attain the exogenously given level of spending. When this economy has multiple competitive equilibria that attain $G^{*}$ (when a Laffer curve is present), the one that achieves the

\footnotetext{
${ }^{4} \mathrm{CK}$ consider an infinite repetition of this game, in which sustainable plans have the potential of delivering outcomes that are better than what can be achieved without commitment in a one-shot situation. Given that my interest lies with commitment, I only consider the one-shot game.
} 
highest welfare is the one with the lowest tax rate, which we call the Ramsey outcome and will denote by $\left(c_{1}^{*}, c_{2}^{*}, k^{*}, \tau^{*}, G^{*}\right)$.

The key question for our purposes is (strict) implementation: can the government behave in such a way to ensure that the Ramsey outcome will prevail and not any other?

Under the assumption of commitment, it is standard to let the government move first and choose $\tau$, taking into account the households' response. I will call this the Ramsey timing.

Formally, the equilibrium of this economy, which we will call Ramsey equilibrium following CK, involves a government policy $\tau^{r}$ and an allocation rule $f(\tau) \equiv\left(c_{1}(\tau), c_{2}(\tau), k(\tau)\right)$ such that:

(i) for each policy $\tau^{\prime}, f\left(\tau^{\prime}\right)$ maximizes the utility of the households given that the tax rate is $\tau^{\prime}$ and given the exogenous level of spending $G^{*}$.

(ii) given $f, \tau^{r}$ is a policy that maximizes

$$
U\left(c_{1}(\tau), c_{2}(\tau), G^{*}\right)
$$

subject to $\tau R k(\tau) \geq G^{*}$.

Under the Ramsey timing, the government can implement the Ramsey outcome simply by setting $\tau=\tau^{*}$. This happens because the household maximization problem has a unique solution for each choice of $\tau$, given $G^{*}$. When the government announces a tax rate of $\tau^{*}$ and households anticipate $G^{*}$, their maximization problem leads them to choose $\left(c_{1}^{*}, c_{2}^{*}, k^{*}\right)$. At this outcome, the government budget constraint holds, which ensures that we are considering a competitive equilibrium.

How does this government policy rule out other equilibrium outcomes? The result hinges on the households believing that the tax rate will be $\tau^{*}$, that spending will be $G^{*}$, and hence that $\left(c_{1}^{*}, c_{2}^{*}, k^{*}\right)$ is optimal, independently of the actions other households will take.

But, is adherence to this policy really feasible? As an example, let us consider the optimal course of action should all households choose $k=0$. In this case, $\left(\tau^{*}, G^{*}\right)$ is physically impossible, because there are no tax revenues. What would the government do? Would $G$ adjust? Would $\tau$ adjust? By assumption, all of these possibilities are ruled out. Uniqueness of an equilibrium is established thus on the assumption that households believe that the government will act in a way 
that is patently impossible under some scenarios. ${ }^{5}$ In this case, an unconditional commitment to $\hat{\tau}$ is indeed feasible. This approach to analyzing government policy under commitment is common to many papers in the macroeconomic literature. ${ }^{6}$

I now describe the alternative "Schelling" timing, under which the government can make binding promises about its conditional course of actions, but must respect its feasibility constraint (2) no matter what households choose. As our previous reasoning shows, if capital-income taxes are the only source of revenues, it is impossible for the government to ensure $G=G^{*}$.

The following two cases show that the government may or may not be able to ensure that the Ramsey outcome is the unique equilibrium outcome (i.e., that the Ramsey outcome is "Schellingimplementable").

First, suppose that household preferences are given by $U\left(V\left(c_{1}, c_{2}\right), G\right)$, with $U_{1}>0$ for all levels of $G$, i.e., government spending does not affect the marginal rate of substitution between current and future consumption. ${ }^{7}$ This case includes the common assumption that government spending is "thrown into the ocean" without affecting household utility.

In this case, the Ramsey outcome is Schelling-implementable. One way to implement it is for the government to set $\tau=\tau^{*}$, and let $G$ adjust as a residual: $G=\tau R K$. Given that the level of $G$ does not affect saving, the optimal choice of $k$ is independent of the choices of other

\footnotetext{
${ }^{5}$ In order to avoid this difficulty, CK in section V.A assume that the government will receive a large penalty $-M$ whenever the economy attains an outcome in which $G^{*}>\tau R K$, where $K$ is aggregate capital. In other words, their solution relies on assuming that it is possible for the government, albeit very costly, to pay for spending from resources that come from outside the model. In private conversation, Chari explained to me that CK implicitly assumed that government spending would have to adjust, rather than being financed from resources outside of the model, and that government spending is assumed to be weakly separable from consumption and the labor supply. The implications of these assumptions are studied below.

${ }^{6}$ Even many papers that do not assume commitment face a similar problem. It is almost universally assumed that the tax rate on labor is set unconditionally before the labor supply is observed, even when no commitment is allowed along many other possible dimensions. This implicit commitment not to revise the tax on labor is open to exactly the same criticism, as the reader can verify e.g. by looking at CK's "no-commitment game".

${ }^{7}$ We can assume that preferences are such that $\left(\tau^{*}, G^{*}\right)$ yields the best competitive equilibrium even when $G$ can vary, or we can still inquire whether the government can implement $\left(\tau^{*}, G^{*}\right)$, independently of this being the best from the households' perspective.
} 
households (that affect aggregate capital). As an example, if all households choose $k=0$, the government can still tax capital income at the rate $\tau^{*}$, and provide no spending. In this case, the optimal choice for an individual would be to save $k^{*}>0$, which implies that $K=0$ cannot be an equilibrium.

Suppose instead preferences are given by $U\left(c_{1}, G c_{2}\right)$. As an example, this may happen because $G$ represents expenses to enforce property rights (such as police) that are needed for households to enjoy private consumption in the second period. With these preferences, there is an equilibrium in which all households choose $k=0$, no matter what the government does. If the aggregate capital is 0 , the government budget constraint implies that $G=0$ independently of the tax rates. When households expect $G=0$, it is optimal to choose $k=0$. As a consequence, no matter what the government strategy is, there always exists an equilibrium in which $k=G=0$.

In this case, the Schelling timing reaches a dramatically different conclusion from the Ramsey timing. In the latter, households believe that $G=G^{*}$, even when there are no resources for this to happen; in the former, households realize that the government may be forced to $G=0$ and it is impossible to rule out an equilibrium with no consumption in the second period. It is worth emphasizing that this does not imply that the economy will necessarily be stuck in such an equilibrium. The government can still set its strategy so that taxes and spending are $\left(\tau^{*}, G^{*}\right)$ if aggregate capital is $k^{*}$. In this case, the Ramsey outcome is still one of the possible competitive equilibria for the economy. What fails is the ability of government policy to select among equilibria and steer the economy to the preferred outcome.

\section{$2.2 \quad$ Increasing Returns}

I consider here an example adapted from Cooper [11]. ${ }^{8}$ In this economy, households choose an effort level $e \in[\underline{e}, \bar{e}]$. Each household has access to a production technology that requires effort and is also affected by the average effort $E$ exerted by other households. The amount produced by a household that chooses effort $e$ is given by

$$
e^{\beta} E^{\gamma}
$$

\footnotetext{
${ }^{8}$ See pages $148-149$.
} 
where $\beta, \gamma>0$. The household preferences over consumption and effort are given by $c-k e^{\theta}$, where $c$ is the consumption level, $k>0$, and $\theta>\beta+\gamma$. The government of this economy can set up a tax administration, which requires a fixed cost $\tau$ to run. If the administration is set up, the government can collect a lump-sum tax $T \in \mathbb{R}_{+}$that can be used to provide a proportional subsidy to production at a rate $s \in \mathbb{R}_{+}$.

The government budget constraint is

$$
\begin{gathered}
T \leq Y \\
s Y \leq T-\tau
\end{gathered}
$$

where $Y$ is aggregate output of the economy. The first constraint stems from the assumption that taxes are collected before the subsidy is paid out.

Each individual household consumes thus

$$
e^{\beta} E^{\gamma}(1+s)-T
$$

If the government does not set up the tax administration, this economy has a unique equilibrium: ${ }^{9}$

$$
\left\{\begin{array}{l}
e=\hat{e} \equiv\left(\frac{\beta}{k \theta}\right)^{\frac{1}{\theta-\beta-\gamma}} \\
y=\hat{y} \equiv \hat{e}^{\beta+\gamma} \\
c=\hat{y}
\end{array}\right.
$$

Depending on the value of $\tau$, the Ramsey outcome either coincides with (6) or is given by

$$
\left\{\begin{array}{l}
e=e^{*} \equiv\left(\frac{\beta+\gamma}{k \theta}\right)^{\frac{1}{\theta-\beta-\gamma}} \\
y=y^{*} \equiv\left(e^{*}\right)^{\beta+\gamma} \\
c=c^{*} \equiv y^{*}-\tau \\
s=\frac{\gamma}{\beta} \\
T=\frac{\gamma}{\beta} y^{*}+\tau
\end{array}\right.
$$

I assume that (7) is the Ramsey outcome, which will happen whenever $\tau$ is not too large.

\footnotetext{
${ }^{9} \mathrm{I}$ assume that $0<\underline{e}<\hat{e}<e^{*}<\bar{e}$, where $\hat{e}<e^{*}$ is not an assumption, but a result.
} 
Cooper studies the Ramsey timing, in which the government sets $(s, T)$ first. In this case, the Ramsey outcome can be implemented by setting $\left(s^{*}, T^{*}\right)$. If each household believes that the government will choose $\left(s^{*}, T^{*}\right)$ independently of the actions of all other households and believes the average effort by other households to be $E$, its maximization problem becomes

$$
\max _{e} e^{\beta} E^{\gamma}\left(1+s^{*}\right)-T^{*}-e^{\theta}
$$

Solving (8) and imposing the equilibrium condition $e=E$, it can be verified that the Ramsey outcome is the unique equilibrium outcome.

The Ramsey timing is unsatisfactory for two reasons:

(i) If all households choose a low effort ( $E$ is sufficiently low), each individual household might not able to meet its tax obligations $T^{*}$, even if it chose $e=\bar{e}$. In this case, the implied consumption would be negative. What should we conclude about the optimal level of effort for a household that believes it will not be able to pay taxes no matter what work effort it chooses? What impact would this have on the actual government revenues in (4)?

(ii) If all households choose a higher effort than $e^{*}$, the government budget constraint (4) fails to hold: the government would not have enough resources to pay its subsidy. However, by assumption households must believe that taxes are still going to be $T^{*}$ and the subsidy is still going to be $s^{*}$, for it is under this assumption that the higher level of effort was ruled out as an equilibrium.

As in the previous section, the Ramsey timing is not an appropriate representation of the strategic interaction between households and the government in this instance. I now propose a more complete description.

I assume that government taxes must be collected before the subsidy is paid out. The lump-sum nature of the tax is translated into the assumption that the government can inflict a very large nonmonetary penalty $P$ on households that fail to pay the due $\operatorname{tax} T$. We assume $-P<\min \left\{-\bar{e}^{\theta},-T\right\}$, so the penalty is sufficiently harsh that any household will want to avoid it if at all possible. The government does not gain any direct benefit from imposing the penalty. 
In order to operate a tax administration and mete penalties out, it is necessary that tax revenues cover at least the fixed cost $\tau .^{10}$

Government revenues from each household are now $T I_{e^{\beta} E^{\gamma}>T}$, where $I$ is the indicator function: the government collects taxes only if the household output exceeds the tax obligation, otherwise no tax is collected and the penalty is imposed. ${ }^{11}$ The government budget constraint is thus

$$
T I_{E^{\beta+\gamma}>T} \geq s Y-\tau
$$

or $T=0$ and $s=0$.

Under the Schelling timing, a strategy for the government is a map from aggregate effort $E^{12}$ into pairs of taxes and subsidies $(T, s) \in \mathbb{R}_{+}$subject to (4) and (9). ${ }^{13}$

Now suppose that $\hat{y}<\tau{ }^{14}$ In this case, if households do not expect the government to provide any subsidies, they will all choose effort $\hat{e}$, leading to a production level $\hat{y}$. If production is $\hat{y}$, there are not enough resources for the government to set up a tax administration: even with commitment, the government will be unable to intervene, validating the expectations that led households to choose $\hat{e}$. Therefore, if $\hat{y}<\tau$, the Ramsey outcome is not Schelling-implementable.

Once feasibility restrictions are taken into account, the subsidization scheme cannot ensure

\footnotetext{
${ }^{10}$ If the policy specifies a smaller tax revenue, the employees of the tax administration will realize that they will not be paid in full and will refuse to work.

${ }^{11} \mathrm{I}$ make this assumption because it is the closest to lump-sum taxation: the household choice of $e$ is not distorted whether it can or cannot meet the tax obligation, and a household will choose to meet the obligation whenever feasible. Other assumptions could be made; while those assumptions will change the nature of the second equilibrium that the government cannot avoid, they typically share the feature that such a second equilibrium exists.

${ }^{12} \mathrm{~A}$ complete description of the environment would specify a government strategy as a function of the distribution of actions taken by private households. Appendix A.1 explains in detail why it is not necessary to consider nondegenerate distributions.

${ }^{13}$ Christiano and Harrison [7] study an implementation problem in an environment similar to this one. While they do not fully consider the details of how the government raises lump-sum taxes, their mechanism relies on an explicit government strategy and is thus more similar to the approach I advocate here.

${ }^{14}$ It is worth pointing out that there is an open set of parameter values that satisfies all of the implicit restrictions that I have assumed. As an example, there is a neighborhood of $\beta=0.9, \gamma=0.6, \theta=1.6, k=0.8, \tau=0.5$, $\underline{e}=0.01, \bar{e}=100$ for which all restrictions hold.
} 
that the economy will attain the Ramsey outcome. The best the government can do is to commit to a strategy that admits the Ramsey outcome as one of the equilibria in the game played by the households; the option to subsidize output offers the government the chance to improve upon the laissez-faire equilibrium, but not the definite ability to coordinate the economy to a welfare-improving equilibrium.

\section{A General Setup}

In this section, I introduce a general setup to formally analyze the implications of commitment. In $§ 3.1$, I introduce the notation and review the standard definition of commitment, based on the Ramsey timing. In $§ 3.2$, I study the Schelling timing and I explain its advantages. $§ 3.3$ generalizes the discussion to a multiperiod environment.

\subsection{Ramsey Timing}

I follow here the notation in Stokey [25]. The players of the economy are a continuum of identical households and a government.

Households choose an action $x$ from a set $X$, and the government chooses an action $y$ from a set $Y$. Given that the focus is on symmetric equilibria, the economy is only described along paths in which all households, except at most a measure 0 set, take the same action. The economy is subject to an aggregate feasibility constraint that requires $(x, y) \in D \subseteq X \times Y$. I will refer to a feasible $(x, y)$ pair as an outcome.

Preferences for the households are described by a function $u: X \times D \rightarrow \mathbb{R},{ }^{15}$ where the first

\footnotetext{
${ }^{15}$ In Stokey [25], individual households are subject to a constraint in their choices, which is represented by a correspondence $H: D \rightarrow X$. This constraint is inconsistent with representing the economy as a game, which is essential for establishing results on implementation. The constraint $H$ would require the choice set of a household to depend on information (the moves of other households) that is not yet available at the moment in which the decision is taken. $H$ is meant to capture individual budget constraints. I will consider applications in which $X$ can be chosen so that $H(x, y)=X \forall(x, y) \in D$, i.e., the households can choose any action $x \in X$ independently of what the government does or other households do. In the first example, this is achieved by assuming that the
} 
argument is the individual household choice and the second is the pair of aggregate choices by (almost) all households and the government.

Government preferences are described by a function $w: D \rightarrow \mathbb{R}$. It is often assumed, though not necessary for our analysis, that the government is "benevolent", i.e., that ${ }^{16}$

$$
w(x, y)=u(x, x, y) \quad \forall(x, y) \in D
$$

A competitive equilibrium is a pair $(x, y)$ with the following properties:

(i) $(x, y) \in D$

(ii) $x=\arg \max _{\xi} u(\xi, x, y)$

As expected, a competitive equilibrium is not a strategic notion of an equilibrium; rather, it only involves an outcome at which each household is taking a best response to what the government and other households are doing. Let $E$ be the set of competitive equilibria.

A Ramsey outcome is a competitive equilibrium $\left(x^{*}, y^{*}\right)$ such that

$$
\left(x^{*}, y^{*}\right)=\arg \max _{(x, y) \in E} w(x, y)
$$

The Ramsey outcome is the best possible outcome among competitive equilibria. The restriction to a competitive equilibrium follows from the assumption that the government does not have access to a way of enforcing directly the actions of each individual household; rather, it can only affect the households' behavior through the choice of $y$. In order to attain this outcome, commitment is often necessary. If this is not the case, the households would have to choose $x$ based on the anticipation of what the government will do, rather than on its actual choice; once $x$ is chosen, the government would no longer perceive $(x, y) \in E$ as a constraint, but would rather take as given the households' choices. This is the basic time-consistency problem.

Figure 3.1 illustrates the Ramsey timing. In this case, the government moves first and commits to an action $y$. Households then respond, with a choice $x$, and an outcome is determined. household choice is about $k$, so that $c_{1}$ and $c_{2}$ are determined by (1). Whenever prices are an important part of the economy, I assume they are explicitly formed through a well-specified market mechanism by the actions of the households and the government, as in Bassetto [2].

${ }^{16}$ The only advantage of (10) is that it provides unambiguous results on the welfare properties of different equilibria. When (10) does not hold, the welfare implications become harder to interpret. 


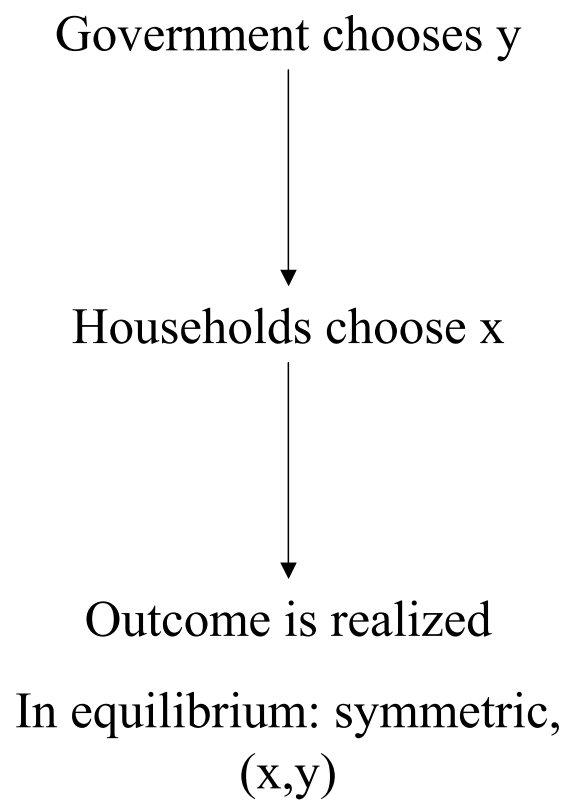

Figure 1: The Ramsey timing (commitment to actions)

In order to define a Ramsey game (and study its equilibrium), CK need to overcome an important difficulty. When the government moves first, the feasibility restriction $(x, y) \in D$ cannot be imposed, since:

(i) by choosing an action $y$ first, the government cannot make sure that the households will choose an action $x$ such that $(x, y) \in D$.

(ii) the restriction to $D$ is a restriction on aggregate quantities and not on individual households. In the game, each household is free to choose any action $x \in X$.

CK extend the set of possible (symmetric) outcomes to $X \times Y$, but set $w(x, y)$ to a very large penalty when $(x, y) \notin D$ so that the government will act in such a way to ensure an outcome in $D$ whenever possible. This is the key difference between their structure, which represents the view of commitment often adopted in macroeconomics, and the one I advocate. In CK's game, violating a feasibility constraint is "less impossible" than violating the terms of commitment. ${ }^{17}$

\footnotetext{
${ }^{17} \mathrm{CK}$ formalize a notion of equilibrium with commitment that others have used. However, their focus is on equilibria in which commitment is not assumed; in their work, the inconsistency about the treatment of the feasibility constraint under commitment is only an additional reason for moving to a game without commitment.
} 
I now turn to the implications of this timing for the ability of the government to attain the best possible competitive equilibrium.

Definition 1 (Ramsey implementability) Let $(x, y)$ be a competitive equilibrium. $(x, y)$ is said to be Ramsey implementable if, for all $x^{\prime} \neq x,\left(x^{\prime}, y\right) \notin E$. If $(x, y)$ is implementable, then $y$ is said to implement it. Similarly, given a set of competitive equilibria $S \subseteq E$, we say that $S$ is implementable if there exists a government action $y$ such that, for any $x^{\prime} \in X$, $\left(x^{\prime}, y\right) \notin S \Rightarrow\left(x^{\prime}, y\right) \notin E$.

A competitive equilibrium $(x, y)$ is implementable if the government can behave in a way that makes $(x, y)$ the inevitable equilibrium outcome.

The definition of implementability does not address the issue of whether the government will choose a strategy that implements $(x, y)$ : it is silent on the incentives of the government.

With the Ramsey timing, the government policy $y$ that implements an outcome $(x, y)$ does not need to be feasible for all choices of $x$; the government can incur the risk of receiving an arbitrarily large penalty if households choose $x$ such that $\left(x, y^{*}\right) \notin D$, because this will never happen on the equilibrium path.

In many applications, the following proposition shows that all competitive equilibria are implementable with the Ramsey timing.

Proposition 1 Suppose the set of competitive equilibria E can be represented as a function of $y$, defined on a subset of $Y$ :

$$
\exists f: Y_{0} \subseteq Y \rightarrow X \text { such that }(x, y) \in E \Longleftrightarrow x=f(y)
$$

Then any competitive equilibrium (and in particular the Ramsey outcome) is implementable.

Proof. Let $(x, y)$ be a competitive equilibrium. Equation (11) implies that $(\hat{x}, y)$ is not a competitive equilibrium unless $\hat{x}=x$. QED. 


\subsection{Committing to Strategies}

In many economic examples, the government cannot really take its action first; rather, commitment is best described as the ability to tie its hands with respect to actions that will be taken later. It is thus more fruitful to model commitment as a process of threats and promises that the government is able to bind itself to; after such threats and promises are made, the interaction between households and the government is subject to all the feasibility restrictions that we would impose on the government if the commitment stage of the game was not present. Before introducing binding promises, we thus model the interaction as it would be without any power to commit.

Households move first and choose $x \in X$. We will consider here only the consequences of almost all households taking the same action; we will not consider what happens when households choose actions according to a nondegenerate distribution. Under the assumptions on preferences that we make, appendix A.1 shows that explicitly considering nondegenerate distributions is irrelevant for implementability. ${ }^{18}$

After the households have moved, the government picks an action $y \in Y$ such that $(x, y) \in D$. We need to assume that $D$ is such that $\forall x \in X, \exists y:(x, y) \in D$. In words, the government must always have at least one feasible action no matter what the households played. This action may depend of course on the specific value of $x$.

Household and government preferences are defined as in §3.1. I assume that $u$ is strictly concave in the first argument and that $X$ is convex, which ensures that, in any equilibrium, all households will take the same choice.

The definition of a competitive equilibrium is also the same as previously. The set of competitive equilibria is unaffected by the difference in timing, because competitive equilibrium is a non-strategic notion of equilibrium.

\footnotetext{
${ }^{18}$ Intuitively, our assumptions ensure that the household problem has a unique optimum. As a consequence, if an outcome envisions a nondegenerate distribution of household choices, it automatically follows that it is not a competitive equilibrium, independently of the government move: some households would be taking a suboptimal choice. Any feasible play by the government after a nondegenerate distribution is enough to rule out such an outcome as an equilibrium path.
} 


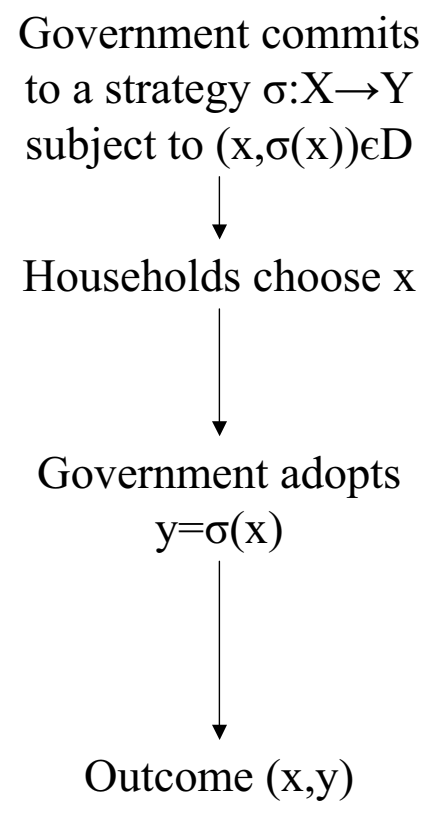

Figure 2: Schelling timing

A strategy for the households is now simply a choice of $x$; a strategy for the government is a function $\sigma^{g}: X \rightarrow Y$ such that $\left(x, \sigma^{g}(x)\right) \in D \forall x \in X$.

We now introduce commitment according to the Schelling timing. In this case, the government can commit to a strategy $\sigma$ before households choose their action $x$, though its action $y$ will be carried out after the households have moved. This timing is displayed in figure 3.2.

Definition 2 (Schelling implementability) A competitive equilibrium $(x, y)$ is Schelling implementable if there exists $\sigma: X \rightarrow Y$ such that

$$
\forall \hat{x} \in X, \hat{x} \neq x \Longrightarrow(\hat{x}, \sigma(\hat{x})) \in D \backslash E
$$

In words, a competitive equilibrium is Schelling-implementable if the government can respond to any choice $\hat{x}$ by the households with some action $y$ that is feasible when all households choose $\hat{x}$ but that is not a competitive equilibrium with $\hat{x}$.

Ramsey implementability and Schelling implementability are distinct. Suppose $(x, y)$ is Ramsey-implementable, but there exists $\hat{x}$ such that $(\hat{x}, y) \notin E$ and $(\hat{x}, \hat{y}) \in E \forall \hat{y}:(\hat{x}, \hat{y}) \in D$. In this case, $y$ is not a feasible government action after the households chose $\hat{x}$; the Ramsey game 
lets the government choose such an action ex ante, but the game without commitment does not. Furthermore, any government response to $\hat{x}$ would validate $\hat{x}$ as part of an equilibrium, so that there is nothing the government can do to persuade households not to play $\hat{x}$ if they believe all other households will play $\hat{x}:(x, y)$ is thus not Schelling implementable.

Let $(x, y)$ instead be Schelling-implementable, and suppose thete exists $(\hat{x}, y) \in E$ with $\hat{x} \neq x$. Then $(x, y)$ is not Ramsey-implementable. By having to choose $y$ first, the government cannot respond to $\hat{x}$ using some other action $\hat{y}$ that does not form a competitive equilibrium with $\hat{x}$; by contrast, with the Schelling timing, the strategy $\sigma^{g}$ that implements $(x, y)$ may prescribe such a response. Notice that this example relies on finding $(\hat{x}, y) \in E$, which is impossible under the assumptions of corollary 1.

The following proposition formalizes the reasoning above:

Proposition 2 In order for $(x, y)$ to be Schelling-implementable, it is neither necessary nor sufficient that $(x, y)$ be Ramsey implementable.

Under the Ramsey timing, by choosing an unconditional action $y$ rather than a conditional response, the government may lose the flexibility that is necessary to implement the desired outcome. In this case, Ramsey implementability is a stronger requirement than Schelling implementability. However, under the Ramsey timing the government has the power to exclude many household choices $x$ as part of the equilibrium outcome simply by setting an action $y$ that is physically impossible when $x$ is chosen. In many applications, this power makes Ramsey implementability a much weaker requirement than Schelling implementability.

The difference between Ramsey and Schelling implementation is very important for policy advice. According to the former, if the set of Ramsey outcomes is implementable, then the government simply needs to set its policy to the preferred outcome; e.g., it only needs to specify a tax rate (or a sequence of tax rates) and a level of spending, or the level of the money supply. Policy advice becomes thus relatively simple. In the latter, implementability simply means that it is possible to design a strategy such that any competitive equilibrium of the game that ensues will be a Ramsey outcome; the role of the policy advisor is thus to design such a strategy, or "reaction function", that will typically involve different actions in response to different choices 
by the households. It is necessary to contemplate all possible choices by the households, and to recommend a policy that is consistent with the Ramsey outcome but that makes it optimal for individual households to deviate from what other households do whenever what they do is not a Ramsey outcome.

\subsection{Many Periods}

I now extend the discussion to dynamic, multiperiod environments. I retain the assumption of convexity of the household's problem which ensures that, in an equilibrium, all households take the same action: this enables me to focus only on histories in which almost all households take the same action and disregard other, more-complex ones.

I characterize the environment in terms of histories, which are defined recursively. ${ }^{19}$ At each time $t$, we denote as $H^{t}$ the set of public histories and $H_{I}^{t}$ the set of private histories. A public history contains the record of play for the government and almost all households up to time $t$. A private history contains the same information, plus the record of past play of the individual household facing such history; this record may be important to assess what actions are feasible for the household in period $t$ (e.g., past saving decisions affect the current opportunities for consumption). At time $t$, the set of feasible actions for a household whose private history is $h_{I}^{t-1}$ is denoted $S_{I t}\left(h_{I}^{t-1}\right)$, and the set of feasible actions for the government is denoted $S_{t}\left(h^{t-1}, x_{t}\right)$, where $x_{t}$ is the action taken by (almost) all households. ${ }^{20} S_{I t}$ is assumed to be a convex-valued correspondence. Starting from the null (public and private) history $h^{-1}=\emptyset$, the sets of public

\footnotetext{
${ }^{19}$ The structure I introduce here is similar to the definition of a game in Osborne and Rubinstein [18].

${ }^{20}$ In the one-shot economy, a crucial difference between Ramsey implementation and Schelling implementation arose from the assumption that the set of feasible actions for the government depends on the actions of the households, so that the government is effectively the second mover within the period. In a multiperiod environment, the same difference may be caused by the fact that the set of feasible actions for the government depends on what households did in previous periods. As a consequence, this important component of the distinction between Ramsey and Schelling implementability would be present even if the government were the first mover within the period. The analysis could thus apply equally well in the case in which $S_{t}$ only depends on $h^{t-1}$ and $S_{I t}$ depends on $h_{I}^{t-1}$ and the government action $y_{t}$.
} 
and private histories are defined recursively as follows:

$$
\begin{gathered}
H^{t}=\left\{\left(h^{t-1}, x_{t}, y_{t}\right) \mid h^{t-1} \in H^{t-1}, x_{t} \in S_{I t}\left(f_{I}\left(h^{t-1}\right)\right), y_{t} \in S_{t}\left(h^{t-1}, x_{t}\right)\right\} \\
H_{I}^{t}=\left\{\left(h_{I}^{t-1}, \xi_{t}, x_{t}, y_{t}\right) \mid h_{I}^{t-1} \in H_{I}^{t-1}, \xi_{t} \in S_{I t}\left(h_{I}^{t-1}\right), x_{t} \in S_{I t}\left(f_{I}\left(f_{P}\left(h_{I}^{t-1}\right)\right)\right), y_{t} \in S_{t}\left(f_{P}\left(h_{I}^{t-1}\right), x_{t}\right)\right\}
\end{gathered}
$$

where $f_{I}$ is a function that maps a public history $h^{t}$ into the private history of a household that has played the same actions as almost all other households and $f_{P}$ is the function that extracts the public component of a private history, i.e.,

$$
\begin{gathered}
f_{I}\left(\left(x_{t}, y_{t}\right)_{t=0}^{s}\right) \equiv\left(x_{t}, x_{t}, y_{t}\right)_{t=0}^{s} \\
f_{P}\left(\left(\xi_{t}, x_{t}, y_{t}\right)_{t=0}^{s}\right) \equiv\left(\left(x_{t}, y_{t}\right)_{t=0}^{s}\right)
\end{gathered}
$$

Let $T$ be the number of periods the game lasts, which could be finite or infinite. Individual outcomes are the elements of $H_{I}^{T}$, and aggregate outcomes are the elements of $H^{T}$. Household preferences over outcomes are given by ${ }^{21}$

$$
\sum_{t=0}^{T} \beta^{t} u\left(\xi_{t}, x_{t}, y_{t}\right)
$$

where $u$ is strictly concave in $\xi$.

A competitive equilibrium is a public history $\left(x_{t}, y_{t}\right)_{t=0}^{T} \in H^{T}$ such that:

$$
\left\{x_{t}\right\}_{t=0}^{T}=\arg \max _{\left\{\xi_{t}\right\}_{t=0}^{T}} \sum_{t=0}^{T} \beta^{t} u\left(\xi_{t}, x_{t}, y_{t}\right)
$$

subject to $\left(\xi_{t}, x_{t}, y_{t}\right)_{t=0}^{T} \in H_{I}^{T}$. In words, a competitive equilibrium is a sequence of actions for the households and the government such that the households' actions are optimal given what the government and the other households are doing. As before, we let $E$ be the set of competitive equilibria.

Competitive equilibria and their welfare properties can be studied without any reference to dynamics: it is a standard result that it does not matter whether all actions are decided upon at time 0 , or they are decided as history unfolds. ${ }^{22}$ As an example, this is the basis for the extension of Ramsey's [19] results on optimal taxation in a static context to dynamic problems. ${ }^{23}$

\footnotetext{
${ }^{21}$ We could consider more-general preferences, as long as they are time consistent.

${ }^{22} \mathrm{I}$ am assuming here that household preferences are time consistent. If not, this would introduce a strategic element of choice within individual households.

${ }^{23}$ Early examples of this vast literature are Lucas and Stokey [15], Chamley [4] and Judd [14].
} 
Definition 3 A competitive equilibrium $\left(x_{t}^{*}, y_{t}^{*}\right)_{t=0}^{T}$ is Ramsey-implementable if, for all $\left\{x_{t}\right\}_{t=0}^{T} \neq$ $\left\{x_{t}^{*}\right\}_{t=0}^{T},\left(x_{t}, y_{t}^{*}\right)_{t=0}^{T} \notin E$.

Under the Ramsey timing, the government moves first and sets its entire sequence of actions; once the government policy is set, households move competitively. As for competitive equilibria, dynamics play no special role for Ramsey implementation. From a strategic perspective, it does not matter whether the government is setting a single action or a single sequence of actions at time 0 .

As in the one-shot economy, Ramsey implementation of a dynamic competitive equilibrium is based on implausible assumptions about household beliefs. Households must believe that the government will play $\left\{y_{t}^{*}\right\}_{t=0}^{T}$ no matter what history will unfold, even though the sequence of government policies is infeasible in some contingencies.

We now turn to Schelling implementation, in which dynamics play an important role: the feasible set of actions for the government evolves over time, which has to be reflected in policy design. $^{24}$

Schelling implementation is based on a government strategy, which is a function $\sigma$ that specifies a feasible action for the government after any nonterminal public history and after each possible choice by the households:

$$
\sigma\left(h^{t}\right) \in S_{t}\left(h^{t}, x_{t}\right) \quad t<T, \forall x_{t} \in S_{I t}\left(f_{I}\left(h^{t}\right)\right)
$$

Let $H(\sigma)$ be the set of all the possible aggregate outcomes for the economy if the government plays according to $\sigma$ :

$$
H(\sigma)=\left\{\left(x_{t}, y_{t}\right)_{t=0}^{T} \in H^{T}: y_{t}=\sigma\left(\left(x_{s}, y_{s}\right)_{s=0}^{t-1}, x_{t}\right), t=0, \ldots, T\right\}
$$

Definition 4 A competitive equilibrium $\left(x_{t}^{*}, y_{t}^{*}\right)_{t=0}^{T}$ is Schelling-implementable if there exists a strategy $\sigma$ such that $H(\sigma) \bigcap E=\left\{\left(x_{t}^{*}, y_{t}^{*}\right)_{t=0}^{T}\right\}:\left(x_{t}^{*}, y_{t}^{*}\right)_{t=0}^{T}$ is the only competitive equilibrium

\footnotetext{
${ }^{24}$ Dynamics play also a second, subtler role in the way the government is able to select among competitive equilibria. In a multiperiod environment, there is scope for distinguishing between Nash implementation, which corresponds to what I present in the main text, and the notion of sequential equilibrium implementation, which is stronger in the case of the games we are studying. This issue is explored in detail in appendix A.2.
} 
among all possible outcomes when the government is committed to behave according to the strategy $\sigma$.

\section{Some Applications}

\subsection{Fiscal Theory of the Price Level}

The fiscal theory of the price level ${ }^{25}$ is based on the assumption that the government can commit to a sequence of real taxes and spending $\left\{\left(T_{t}, G_{t}\right)\right\}_{t=0}^{\infty}$ that can violate the present-value budget constraint for some price levels.

Compared to the examples in the previous sections, the fiscal theory of the price level is much more complex. This is partly of course because the environment is much richer, but mainly because the definition of a competitive equilibrium includes a sequence of prices that are not a choice of any player in the economy.

In order to define a competitive equilibrium, it is not necessary to explain the process that leads to a price $p$ out of the actions of the households $(x)$ and of the government $(y)$. Within a competitive equilibrium, both $x$ and $y$ are held fixed; there is no difficulty in adding a third element to the definition, the price system $p$, that is also taken as given.

Ramsey implementation shares the simplicity of competitive equilibria. To check whether a competitive equilibrium $\left(x^{*}, y^{*}, p^{*}\right)$ is Ramsey-implementable, it is sufficient to know whether there exists a unique competitive equilibrium in which $y=y^{*}$.

Unfortunately, Ramsey implementation does not allow a proper distinction between equilibrium conditions and restrictions on government policy, such as its budget constraint. The failure of this distinction is the main cause the debate on the fiscal theory has been so contentious.

To study Schelling implementation, it becomes crucial to establish which actions each of the players in the economy can take in all contingencies. This is impossible without a full description of the strategic environment as an anonymous game, that must include an explicit account of the way prices form out of the actions of the government and the households. In the case of the

\footnotetext{
${ }^{25}$ See Sims [24], Woodford [28], Cochrane [9].
} 
fiscal theory of the price level, I analyze such a game in detail in Bassetto [2]. In that paper, I do not overturn the conclusion that fiscal policy can be used to select among the many equilibria consistent with an interest-rate peg. However, I show that the policy rule the fiscal theory is based on involves actions that are impossible in some contingencies and is thus not a strategy of the game. A correct strategy that implements a given equilibrium is significantly different from an unconditional commitment to a sequence $\left\{\left(T_{t}, G_{t}\right)\right\}_{t=0}^{\infty}$, and this difference has important implications for policy advice and for evaluating the likelihood that government commitment can be sustained.

\subsection{Monetary Policy Rules}

In recent years, there has been significant research on the welfare and equilibrium determinacy properties of monetary policy rules. ${ }^{26}$ The goal of this research is to find how monetary policy can be used to implement desirable equilibrium outcomes.

Svensson [26] and Svensson and Woodford [27] distinguish between a policy rule and a reaction function. A policy rule is a "prescribed guide for monetary-policy conduct." It usually takes the form of a simple relationship that may involve government policy, exogenous variables and endogenous variables, both past, present and future (in expectation). A reaction function "specifies the central bank's instrument as a function of predetermined endogenous or exogenous variables observable to the central bank at the time that it sets the instrument." The solution to any implementation problem should thus include a reaction function and not simply a policy rule. A policy rule may only be useful as a simple tool to evaluate whether the government is adhering to its commitment. For this purpose, it might have the advantage of being much simpler and hence more transparent than the reaction function itself.

A reaction function corresponds to what I called in this paper a government strategy, so the analysis I developed here supports the view that implementation should be studied at the level of government reaction functions. Svensson and Woodford [27] are mainly focused on interest-rate rules, in which the instrument used by the central bank is the nominal interest rate. The only

\footnotetext{
${ }^{26}$ See e.g. Clarida, Galí and Gertler [8] and references therein.
} 
restriction they identify is that this instrument should be a function of predetermined variables only, a necessary requirement for a strategy in a game. A fuller description of the economy as a game is likely to entail further restrictions. As an example, Schmitt-Grohé and Uribe [23] study the implications of Taylor rules in which interest rates are allowed to be negative in some contingencies. Whether the nonnegativity constraint on nominal interest rates should be viewed as an equilibrium condition or a restriction on government policy can only be ascertained within a fully developed game, in which a government strategy can be more precisely defined.

\subsection{Sovereign Debt Crises}

Most models of sovereign debt and/or exchange rate crises have worked under the assumption that the government does not have the ability to commit to its policy. ${ }^{27}$

I present here a model in which it is not lack of commitment, but rather lack of options that may prevent the government from averting a self-fulfilling economic downturn, whether accompanied by a sovereign default or not.

I consider a small open economy, populated by a continuum (of measure 1) of domestic households, whose preferences are $u\left(c_{1}, c_{2}, l\right)$, where $c_{1}$ is consumption of a domestically-produced good, $c_{2}$ is consumption of an imported good and $l$ is the labor supply. $u$ is strictly concave, strictly increasing in consumption and strictly decreasing in the labor supply. The economy lasts for a single period. A household that supplies $l$ units of labor produces output in an amount $l+q$, where $q$ is a random variable, common to all households, with an almost everywhere continuous density function $f(q)$ on a compact interval $[\underline{q}, \bar{q}]{ }^{28}$ The total endowment of time is $\bar{l}$ and either $\underline{q} \geq 0$ or a household must supply at least $\underline{q}$ units of time. The world price of the domestic good relative to the import is 1 . The economy has a government that owes $B$ units (of either

\footnotetext{
${ }^{27}$ Some examples include Alesina, Prati and Tabellini [1], Calvo [3], Cole and Kehoe [10], Giavazzi and Pagano [13] and Sachs, Tornell and Velasco [20].

${ }^{28}$ The presence of the shock and the assumption that the government only observes total output prevent the use of discontinuous strategies to generate nonexistence of an equilibrium when households expect a default. The results in the text apply for intervals $[\underline{q}, \bar{q}]$ that are arbitrarily small and close to 0 , which shows the nonexistence obtained through discontinuous strategies to be not robust.
} 
good) to some foreign creditors at the end of the period. The government does not have any expenses, but can use a proportional tax on output to raise resources to repay its debt. If the government defaults on its debt, foreign trade is disrupted; we make the extreme assumption that households are completely excluded from foreign trade and must thus consume only the domestically-produced output.

The timing of the economy is as follows:

(i) The government commits to a (measurable) strategy which it will follow in part (iv).

(ii) Households choose their labor supply. The realization of the shock is not yet known when they make their decision.

(iii) The production shock $q$ is realized.

(iv) The government sets a tax rate $\tau$ and a repayment rate $\delta$, subject to the budget constraint

$$
\tau(L+q) \geq \delta B
$$

where $L$ is the aggregate labor supply. We assume the government does not observe $L$ or $q$ independently, but just aggregate output, and its strategy must thus be a function of output.

(v) If $\delta \geq 1$, households trade in the foreign markets at the world price of 1 .

Let $C_{1}$ and $C_{2}$ be the aggregate consumption of the domestic and imported good respectively. A competitive equilibrium is given by a labor supply $L$ and a random vector $\left(C_{1}, C_{2}, \tau, \delta\right)$, adapted to $q$, such that: ${ }^{29}$

(i) Households are maximizing their utility given the technology, taxes, and the opportunity

\footnotetext{
${ }^{29}$ There is no contradiction between the previous assumption that the government cannot set its strategy as a function $q$ and the definition of a competitive equilibrium, in which $\tau$ and $\delta$ are adapted to $q$. Within a competitive equilibrium, $L$ is known, and hence a function of aggregate output is equivalent to a function of the shock.
} 
to trade:

$$
\begin{gathered}
u_{l}\left(C_{1}, C_{2}, L\right)=E\left[(1-\tau) u_{1}\left(C_{1}, C_{2}, L\right)\right] \\
u_{1}\left(C_{1}, C_{2}, L\right)=u_{2}\left(C_{1}, C_{2}, L\right) \quad \text { if } \delta \geq 1 \\
C_{2}=0 \quad \text { if } \delta<1 \\
C_{1}+C_{2}=(1-\tau)(L+q)
\end{gathered}
$$

(ii) The government budget constraint (13) is satisfied.

We assume the government only cares about domestic households, so we define the Ramsey outcome as the competitive equilibrium that has the highest welfare for them. We assume that parameter values are such that the Ramsey outcome $\left(L^{*}, C_{1}^{*}, C_{2}^{*}, \tau^{*}, \delta^{*}\right)$ involves no default, independently of the realization of $q: \delta^{*} \equiv 1$.

Whether the government can implement the Ramsey outcome relies crucially on the properties of the labor supply. To show this, we first define the best reply for a household when the government is committed to a strategy $\sigma$ and other households choose a labor supply $L$. We denote the best reply as $\left(\hat{c}_{1}, \hat{c}_{2}, \hat{l}\right)(L, \sigma)$, which is given by

$$
\begin{array}{r}
\left(\hat{c}_{1}, \hat{c}_{2}, \hat{l}\right)(L, \sigma)=\underset{c_{1}, c_{2}, l}{\arg \max _{1}} E\left[u\left(c_{1}, c_{2}, l\right)\right] \quad \text { subject to } \\
c_{1}+c_{2} \leq\left[1-\tau_{\sigma}(L+q)\right](l+q) \\
c_{2}=0 \text { if } \delta_{\sigma}(L+q)<1
\end{array}
$$

where $\tau_{\sigma}$ and $\delta_{\sigma}$ are the tax rate and repayment rate that form the strategy $\sigma$.

Proposition 3 The Ramsey outcome is implementable if and only if there is a government strategy $\sigma$ such that $\hat{l}\left(L^{*}, \sigma\right)=L^{*}$ and

$$
\hat{l}(L, \sigma)>L \quad \forall L \in\left[0, L^{*}\right)
$$

The proof of the proposition is presented in the appendix, along with numerical examples in which (16) does and does not hold. We discuss here the intuition. The crucial problem for the government is how to respond to low levels of output. In order to repay foreign debt, the government would need to raise the tax rate above the Ramsey level; however, this discourages 
production and may be a source of a self-fulfilling downturn when preferences are such that a Laffer curve arises. Alternatively, the government may respond by defaulting on foreign debt; however, the anticipated inability to engage in foreign trade can also be a disincentive for households to work, validating once more the expectations that led to a low output level. When the Ramsey equilibrium is implementable, the government can commit to an appropriate mix of higher taxes and/or default such that $\hat{l}(L, \sigma)>L$ when $L<L^{*}$ : when the expected labor supply is below the Ramsey level, it is always optimal for an individual household to work somewhat more than the others, which rules out a second equilibrium. When the condition is not met, the government has no instrument to avoid a second equilibrium, characterized by a low output and labor supply. ${ }^{30}$

When the Ramsey outcome is implementable, the appropriate advice calls for building institutions capable to overcome the potential time-inconsistency problem. ${ }^{31}$ As an example, the country could delegate the choice of a tax rate to an independent authority, shielded from political pressure in the short run. ${ }^{32}$ When the Ramsey outcome is not implementable, the previous remedies alone cannot overcome the risk of a self-fulfilling depression. This has important implications when thinking of ways to avoid sovereign debt crises such as the one that has affected Argentina recently.

\section{Conclusion}

In many macroeconomic problems, the policy actions available to the government depend on previous choices made by the private sector. In this paper, I have shown that modelling government commitment as the ability to take (or set) its actions before any other player moves is

\footnotetext{
${ }^{30} \mathrm{We}$ only discussed the case in which $L<L^{*}$. It is very easy for the government to prevent any equilibrium in which the labor supply is higher than Ramsey: it simply needs to commit to raise exactly enough taxes to repay foreign debt, which can be done with a lower tax rate than the one implied by the Ramsey outcome.

${ }^{31}$ Time inconsistency arises in the example because the government can vary its tax rate on output after households have made their labor choice.

${ }^{32}$ Holding infrequent elections as opposed to continuous referenda may be one way societies deal with the problem.
} 
unsatisfactory from the perspective of designing optimal policy schemes. When the potential for multiple equilibria is present, this approach may also paint a misleading picture of the ability of the government to determine the equilibrium outcome that will prevail. I have presented an alternative description of the strategic interaction between the government and private agents, one in which the ability of the government to commit corresponds to the ability to set a strategy that it will adhere to.

In the examples I have presented, the restrictions on government policy came from clear and unavoidable physical constraints, such as the impossibility of spending resources that do not exist. The approach developed here can also be useful for constitutional design, in which institutions with limited commitment power are studied. Rather than merely reflecting physical constraints, the restrictions on the strategies available to the government would then come from the explicit model of these further limits.

\section{A Appendix}

\section{A.1 Nonsymmetric Outcomes}

The environment we described in $§ 3.2$ is not a full description of a game, in that only symmetric histories are considered. We show here that, under our assumptions, considering nonsymmetric outcomes is redundant to establish what can be implemented.

To fully describe an anonymous game, let $(X, \mathcal{X})$ be a measurable space, and let $M$ be the set of probability measures over $(X, \mathcal{X})$. After the households have moved, the government observes the distribution of their choices (but not the individual actions), which can be any element $\mu \in M$. In the main text, we only focus on the case in which $\mu$ is degenerate, attributing probability 1 to a specific element of $X$. The set of possible aggregate outcomes for the game is now expanded to be $\hat{D} \subseteq M \times Y$ : it contains a distribution of actions for the households $\mu$ and a government action $y$. The relationship between $\hat{D}$ and $D$ is the following:

$$
(x, y) \in D \Longleftrightarrow\left(\delta_{x}, y\right) \in \hat{D}
$$

where $\delta_{x}$ is the measure that attributes probability 1 to $\{x\}$. As we did for $D$, we need to 
assume that the government has at least one feasible action after any possible history of the game: $\forall \mu \in M, \exists y:(\mu, y) \in \hat{D}$.

It is likewise necessary to extend household and government preferences to $X \times \hat{D}$ and $\hat{D}$ respectively. Crucially, we assume that the household utility function $u$ is strictly concave in its first argument for each $(\mu, y) \in \hat{D}$.

A government strategy is now a mapping $\sigma: M \rightarrow Y$ such that $(\mu, \sigma(\mu)) \in \hat{D} \forall \mu \in M$.

Schelling implementation corresponds to a specific mechanism design problem. Once the government has committed to play a specific strategy $\sigma$, what remains is an (anonymous) game among households only, whose payoff structure depends on the way the government is committed to respond to those actions. A choice of $\sigma$ corresponds thus to choosing a specific game that the households will play.

The following proposition shows the connection between competitive equilibria as described in the main text and the Nash equilibria of the games the government can design by its choice of $\sigma$.

Proposition 4 (i) Let $(x, y) \in E$. Then $\left(\delta_{x}, y\right)$ is a Nash equilibrium outcome for the game that ensues whenever the government commits to a strategy such that $\sigma\left(\delta_{x}\right)=y$.

(ii) Let $(\mu, y)$ be a Nash equilibrium outcome in a game after the government has committed to a strategy $\sigma$. Then $\mu$ attributes probability 1 to a single point $x \in X$, and $(x, y)$ is a competitive equilibrium.

Proof.

(i) Immediate from the definition of Nash equilibrium and competitive equilibrium.

(ii) By strict concavity of $u$, we know that $\arg \max _{\xi} u(\xi, \mu, y)$ is unique. This implies that the support of an equilibrium distribution $\mu$ must be a singleton. The fact that a Nash equilibrium $\left(\delta_{x}, y\right)$ coincides with a competitive equilibrium $(x, y)$ follows immediately from the appropriate definitions. 
The relationship between Nash equilibria and competitive equilibria has an immediate counterpart for the implementation problem. A competitive equilibrium $(x, y)$ is Schelling implementable if and only if the government can design a game among households (by choice of $\sigma$ ) that has $\left(\delta_{x}, y\right)$ as its unique Nash equilibrium outcome. Since nondegenerate distributions $\mu$ cannot be an equilibrium outcome no matter what choice the government takes, it is unnecessary to specify how the government would react in such a case. This is the reason we focus in the main text only on how the government responds to (almost) all households taking the same action.

\section{A.2 Nash vs. Sequential Equilibrium Implementation in Multiperiod Settings}

As for the one-period version of the game, the multiperiod environment of $\S 3.3$ can also be described as an anonymous game, if a full description of the consequences of nondegenerate distributions is included. However, the assumption of strict concavity of the households' utility function implies that the results of $\S$ A.1 still hold: in particular, all Nash equilibrium outcomes of the game involve all households taking the same actions.

When households are called to move more than once, a distinction arises between Nash and sequential equilibria. ${ }^{33}$ Accordingly, we distinguish between Nash implementation, in which the government designs a game that has a unique Nash equilibrium outcome, and sequential equilibrium implementation, in which the government designs a game that has a unique sequentialequilibrium outcome. Unlike what happens in games with a finite number of players, implementation in sequential equilibrium is here necessarily a stronger notion than Nash implementation. In games with a finite number of players, implementation in sequential equilibrium allows for the design of games that have a unique sequential equilibrium but more than one Nash equilibrium.

\footnotetext{
${ }^{33}$ In an anonymous game, we cannot properly speak of subgame-perfect equilibria, because the actions of each individual household are never observed. However, the distribution of actions of the households is observed; for each household and for the government, this is the only payoff-relevant aspect of the actions of other households. We only analyze equilibria in which a household is thus indifferent among all nodes of an information set and will take the same choice independently of the belief over the specific node the game is at within the information set. For this reason, we can omit specifying beliefs.
} 
This does not happen in anonymous games with a continuum of players, in which each player's individual move does not have any impact on other players' actions. Both in games with a finite number of players and in anonymous games, Nash implementation allows for the design of games that have a unique Nash equilibrium but potentially no sequential equilibria. ${ }^{34}$

The following example clarifies the distinction: in the example, the Ramsey outcome is Nash implementable but not implementable in sequential equilibrium.

Consider repeating twice the first example of section (2). To distinguish between the timing within each repetition and across repetitions, we now call stages the "periods" within each repetition, and we use the word "period" to refer to the repetition number. Neither the households nor the government are allowed to save from one repetition to the next, so that the two periods are independent, unless the strategies of the government and/or the households dictate secondperiod choices that depend on first-period actions. We assume that preferences in the first period are given by $U\left(c_{11}, G_{1} c_{21}\right)$ and preferences in the second period are given by $U\left(V\left(c_{12}, c_{22}\right), G_{2}\right)$, where $c_{i j}$ is the consumption in stage $i$ of period $j$ and $G_{i}$ is the provision of the public good in period $i$. Let $\tau_{i}$ be the tax rate in period $i$.We use $*$ superscripts to denote Ramsey allocations and policies. Given that the two periods are independent of each other, we might expect that the government can guarantee the Ramsey outcome in the second period, but not in the first. We now show that this is true for sequential equilibrium implementation, but that the Ramsey outcome is implementable in Nash equilibrium.

Let $\sigma$ be a government strategy such that, if the government is committed to follow $\sigma$, the game among households has a sequential equilibrium whose outcome is Ramsey. Let $\sigma^{h}$ be the household strategy in such an equilibrium. We show that there also is a sequential equilibrium in which $c_{21}=G_{1}=0$. The new equilibrium has the same strategy in period 2 , but it prescribes households to choose $c_{11}=\omega$ in the first period. We now work backwards to check that this is indeed a sequential equilibrium. In the second period, independently of the history $h_{1}$ up to that point, $\sigma^{h}\left(h_{1}\right)$ must prescribe an action that is optimal for the households given that other households will also play $\sigma^{h}\left(h_{1}\right)$ and the government will respond by $\sigma\left(h_{1}, \sigma^{h}\left(h_{1}\right)\right)$. This is true

\footnotetext{
${ }^{34}$ In standard mechanism-design problems, a common trick to obtain Nash implementation is to design a game in which an "integer game" with no equilibrium follows any undesired outcome.
} 
in particular even after the history in which almost all households chose $c_{11}=\omega$, even though that history is not on the equilibrium path for the original strategy $\sigma^{h}$. In the first period, it is optimal for a household to choose $c_{11}=\omega$ whenever it expects $G_{1}=0$. As we already observed, $G_{1}$ is necessarily 0 if all households choose $c_{11}=\omega$. It thus follows that the modified strategy is indeed a sequential equilibrium.

We now display a government strategy that implements the Ramsey outcome in a Nash equilibrium:

$$
\sigma\left(c_{11}, \tau_{1}, c_{12}\right)= \begin{cases}\sigma\left(c_{11}\right)=\tau_{1}^{*} \quad \forall c_{11} \in[0, \omega] \\ 0 \quad \text { if } c_{11} \neq c_{11}^{*} \text { and } c_{12}=c_{12}^{*} \\ \tau_{2}^{*} \quad \text { otherwise }\end{cases}
$$

We only defined the strategy for histories in which almost all households take the same action; any specification for nondegenerate distributions could be added without altering the results. If the government adopts this strategy and households do not play $c_{11}=c_{11}^{*}$ in the first period, there is no equilibrium in the second period: the government strategy is designed so that a household would always have an incentive to deviate from what other households do. By contrast, if $c_{11}=c_{11}^{*}$ in the first period, then in the second period there is only one equilibrium, in which the second-period Ramsey outcome is attained.

The definition of Schelling implementability in the main text corresponds to Nash implementation in this mechanism design problem, and was chosen because of its simplicity.

\section{A.3 Proof of Proposition 3}

First, suppose a strategy such that (16) holds can be found; let such a strategy be $\sigma$. We prove that the following strategy implements the Ramsey outcome:

$$
\tilde{\sigma}(z) \equiv\left(\tau_{\tilde{\sigma}}, \delta_{\tilde{\sigma}}\right)(z)= \begin{cases}\sigma(z) & \text { if } z \leq \bar{L}^{*}+\bar{q} \\ (B / z, 1) & \text { otherwise }\end{cases}
$$

$\hat{\sigma}$ and $\sigma$ coincide for all the levels of output that are possible when the labor supply is at most $L^{*}$. As a consequence $\hat{l}(L, \sigma)=\hat{l}(L, \tilde{\sigma})$ if $L \leq L^{*}$, which implies that there can be no equilibria 
with a labor supply below $L^{*}$ if the government commits to $\tilde{\sigma}$. With this strategy, we also prove by contradiction that there can be no equilibrium with $\tilde{L}>L^{*}$. If such equilibrium existed, equation (19) implies that it would entail no default and a tax rate that is lower than Ramsey's for each realization of $q$. However, it is easy to show that household welfare is a decreasing function of the tax rate for a given $\delta$; as a consequence, the equilibrium at $\tilde{L}$ would have higher welfare than the one at $L^{*}$, which contradicts $L^{*}$ being part of the Ramsey outcome.

Now, suppose instead that there is no strategy such that (16) holds. We first prove that, given any strategy $\sigma, \hat{l}(L, \sigma)$ is continuous in $L$. Define

$$
v(l, q, \tau, \delta)=\max _{c_{1}, c_{2}} u\left(c_{1}, c_{2}, l\right)
$$

subject to $c_{1}+c_{2} \leq(1-\tau)(l+q)$ and to $c_{2}=0$ if $\delta<1 . v$ is the indirect function after uncertainty is resolved for a household that has chosen a labor supply $l$. $v$ is continuous in $(l, q, \tau)$, but it is discontinuous in $\delta$; it is also strictly concave in $l$. Given a government strategy $\sigma$, the function $\hat{l}$ is defined as

$$
\begin{aligned}
\hat{l}(L, \sigma)= & \arg \max _{l} \int_{\underline{q}}^{\bar{q}} v\left(l, q, \tau_{\sigma}(L+q), \delta_{\sigma}(L+q)\right) f(q) d q= \\
& \arg \max _{l} \int_{L+\underline{q}}^{L+\bar{q}} v\left(l, z-L, \tau_{\sigma}(z), \delta_{\sigma}(z)\right) f(z-L) d z
\end{aligned}
$$

Continuity of $\hat{l}$ in $L$ follows thus from the theorem of the maximum. Given that the labor supply must be nonnegative, it follows that $\hat{l}(0, \sigma) \geq 0$. If equation (16) does not hold, it follows that there must be a fixed point of the function $\hat{l}$ at a level that is strictly smaller than $L^{*}$, which implies that $L^{*}$ is not the unique equilibrium. The exact location of the second equilibrium (or of the other equilibria, if there are more than 1) depends on the government strategy $\sigma$, and will usually not happen at $L=0$.

To provide examples in which Ramsey is or is not implementable, we consider the following preferences:

$$
u\left(c_{1}, c_{2}, l\right)=\frac{\alpha_{1}}{1-\gamma} c_{1}^{1-\gamma}+\frac{\alpha_{2}}{1-\gamma} c_{2}^{1-\gamma}-\alpha_{3} l
$$

Simple algebra shows that the function $\hat{l}$ is implicitly defined as follows:

$$
\alpha_{3}=E\left\{\left[\alpha_{1}^{1 / \gamma}+\alpha_{2}^{1 / \gamma} I_{\delta_{\sigma}(L+q) \geq 1}\right](\hat{l}+q)^{-\gamma}\left[1-\tau_{\sigma}(L+q)\right]^{1-\gamma}\right\}
$$


We assume that $\gamma<1$, otherwise utility would not be well defined in the case of a government default. In this case, $\hat{l}$ is a decreasing function of the tax rate. From (21), it follows that the following strategy maximizes $\hat{l}$ at all levels of $L$ :

$$
\left(\tau_{\sigma}, \delta_{\sigma}\right)(z)= \begin{cases}(B / z, 1) & \text { if }\left(\alpha_{1}^{1 / \gamma}+\alpha_{2}^{1 / \gamma}\right)(1-B / z)^{1-\gamma}>\alpha_{1} \\ (0,0) & \text { otherwise }\end{cases}
$$

The Ramsey outcome is the solution to the following problem:

$$
\max _{\{\tau(q), \delta(q), L, \lambda(L+q)\}} E\left\{\frac{\lambda(L+q)^{1-1 / \gamma}}{1-\gamma}\left[\alpha_{1}^{1 / \gamma}+\alpha_{2}^{1 / \gamma} I_{\delta(q) \geq 1}\right]\right\}-\alpha_{3} L
$$

subject to

$$
\begin{aligned}
\lambda(L+q) & =\left[\alpha_{1}^{1 / \gamma}+\alpha_{2}^{1 / \gamma} I_{\delta(q) \geq 1}\right]^{\gamma}(L+q)^{-\gamma}(1-\tau(q))^{-\gamma} \\
\alpha_{3} & =E\left\{\left[\alpha_{1}^{1 / \gamma}+\alpha_{2}^{1 / \gamma} I_{\delta(q) \geq 1}\right]^{\gamma}(L+q)^{-\gamma}(1-\tau(q))^{1-\gamma}\right\}
\end{aligned}
$$

where $\tau(q)$ and $\delta(q)$ are the equilibrium tax and repayment rate as a function of the shock, and $\lambda(L+q)$ is the Lagrange multiplier for a household that worked $L$ units of time and has to allocate its resources across the two goods, when the shock is $q$.

The solution to the Ramsey problem yields a tax and default policy that coincides with (22) for all levels of output that are possible in the equilibrium. For the purpose of implementation, the government can instead adopt any choice of taxes and default rates, subject to its budget constraint, for output levels that are not possible in the Ramsey outcome.

However, we can check whether the condition of proposition 3 holds by simply looking at the strategy given by (22): if condition (16) is satisfied for this strategy, then adopting it implements the Ramsey outcome; if (16) does not hold for this strategy, then it cannot hold for any other strategy, given that all others imply lower levels of $\hat{l}$.

Whether the Ramsey outcome is or is not implementable depends on numerical values of the parameters. As an example, for $\alpha_{1}=1, \alpha_{2}=1.5, \gamma=0.5, B=1$ and $q$ uniformly distributed between -0.01 and +0.01 , the Ramsey outcome involves no default if $\alpha_{3}<0.89$, but it is implementable only if $\alpha_{3}<0.83$. For a value such as $\alpha_{3}=0.85$, the strategy given by $(22)$ implies 3 possible equilibrium outcomes: in the first, default occurs for sure and the labor supply 
is approximately 1.36; in the second, no default occurs, the labor supply is approximately 1.53, the (stochastic) tax rate oscillates close to $65 \%$ and the economy is in the downward-sloping range of the Laffer curve; finally, in the Ramsey outcome no default occurs, the labor supply is approximately 2.87 and the tax rate oscillates close to $35 \%$. By adopting different strategies, the government can move the location of the equilibrium outcomes; however, the theorem implies that there will always be one in which the labor supply is at or below 1.36.

\section{References}

[1] Alberto Alesina, Alessandro Prati, and Guido Tabellini. Public Confidence and Debt Management: A Model and a Case Study of Italy. In Rudiger Dornbusch and Mario Draghi, editors, Public Debt Management: Theory and History, pages 94-118. Cambridge University Press, 1990.

[2] Marco Bassetto. A Game-Theoretic View of the Fiscal Theory of the Price Level. Econometrica, 2002. forthcoming.

[3] Guillermo A. Calvo. Servicing the Public Debt: The Role of Expectations. American Economic Review, 78(4):647-661, 1988.

[4] Christophe Chamley. Optimal Taxation of Capital Income in General Equilibrium with Infinite Lives. Econometrica, 54:607-622, 1986.

[5] V. V. Chari and Patrick J. Kehoe. Sustainable Plans. Journal of Political Economy, 98(4):783-801, 1990.

[6] V.V. Chari and Patrick J. Kehoe. Optimal Fiscal and Monetary Policy. In John B. Taylor and Michael Woodford, editors, Handbook of Macroeconomics. Volume 1C, chapter 26. Elsevier Science, North Holland, 1999.

[7] Lawrence J. Christiano and Sharon G. Harrison. Chaos, Sunspots and Automatic Stabilizers. Journal of Monetary Economics, 44(1):3-31, 1999. 
[8] Richard Clarida, Jordi Galí and Mark Gertler. The Science of Monetary Policy: A New Keynesian Perspective. Journal of Economic Literature, 37(4):1661-1707, 1999.

[9] John H. Cochrane. Money as Stock: Price Level Determination with no Money Demand. NBER Working Paper, 7498, 2000.

[10] Harold L. Cole and Timothy J. Kehoe. Self-Fulfilling Debt Crises. Review of Economic Studies, 67(1):91-116, 2000.

[11] Russell W. Cooper. Coordination Games: Complementarities and Macroeconomics. Cambridge University Press, 1999.

[12] Stanley Fischer. Dynamic Inconsistency, Cooperation and the Benevolent Dissembling Government. Journal of Economic Dynamics and Control, 2(1):93-107, 1980.

[13] Francesco Giavazzi and Marco Pagano. Confidence Crises and Public Debt Management. In Rudiger Dornbusch and Mario Draghi, editors, Public Debt Management: Theory and History, pages 125-143. Cambridge University Press, 1990.

[14] Kenneth L. Judd. Redistributive Taxation in a Simple Perfect Foresight Model. Journal of Public Economics, 28:59-83, 1985.

[15] Robert E. Lucas, Jr. and Nancy L. Stokey. Optimal Fiscal and Monetary Policy in an Economy without Capital. Journal of Monetary Economics, 12:55-93, 1983.

[16] Kiminori Matsuyama. Sunspot Equilibria (Rational Bubbles) in a Model of Money-in-theUtility-Function. Journal of Monetary Economics, 25(1):137-144, 1990.

[17] Kiminori Matsuyama. Endogenous Price Fluctuations in an Optimizing Model of a Monetary Economy. Econometrica, 59(6):1617-1631, 1991.

[18] Martin J. Osborne and Ariel Rubinstein. A Course in Game Theory. MIT Press, 1994.

[19] Frank P. Ramsey. A Contribution of the Theory of Taxation. Economic Journal, 37:47-61, 1927. 
[20] Jeffrey D. Sachs, Aaron Tornell, and Andres Velasco. The Mexican Peso Crisis: Sudden Death or Death Foretold? Journal of International Economics, 41(4):265-283, 1996.

[21] Thomas J. Sargent and Neil Wallace. "Rational" Expectations, the Optimal Monetary Instrument, and the Optimal Money Supply Rule. Journal of Political Economy, 83(2):241$254,1975$.

[22] Thomas C. Schelling. The Strategy of Conflict. Harvard University Press, 1960.

[23] Stephanie Schmitt-Grohé and Martin Uribe. Liquidity Traps with Global Taylor Rules. Mimeo, University of Pennsylvania and Rutgers University, 2000.

[24] Christopher A. Sims. A Simple Model for Study of the Determination of the Price Level and the Interaction of Monetary and Fiscal Policy. Economic Theory, 4(3):381-399, 1994.

[25] Nancy L. Stokey. Credible Public Policy. Journal of Economic Dynamics and Control, 15:627-656, 1991.

[26] Lars E.O. Svensson. Inflation Targeting as a Monetary Policy Rule. Journal of Monetary Economics, 43(3):607-654, 1999.

[27] Lars E.O. Svensson and Michael Woodford. Implementing Optimal Policy through InflationForecast Targeting. Mimeo, Princeton University, 1999.

[28] Michael Woodford. Monetary Policy and Price Level Determinacy in a Cash-in-Advance Economy. Economic Theory, 4(3):345-380, 1994. 